\title{
Antipruritic Effect
}

National Cancer Institute

\section{Source}

National Cancer Institute. Antipruritic Effect. NCI Thesaurus. Code C40859.

An Antipruritic Effect involves suppression of an itching sensation caused by histamine stimulation of epidermal nerve endings. Inhibition of histamine or histamine release can produce an antipruritic effect. 